\title{
Verhoor van minderjarige slachtoffers
}

\section{Faber ${ }^{*}$}

\section{Inleiding}

Eén van mijn taken als jeugd- en zedenrechercheur van de Regiopolitie Groningen is het horen van kinderen die slachtoffer of getuige zijn geweest van een ernstig misdrijf; daarbij gaat het voornamelijk om zedenmisdrijven. Binnen de politie in Nederland is er een speciale methode ontwikkeld om dergelijke verhoren op een verantwoorde en zo professioneel mogelijke manier af te nemen. Voordat ik nader op deze methode inga, lijkt het mij goed om stil te staan bij de vraag 'Wat is een goed verhoor?'. Deze vraag is moeilijk te beantwoorden. In z'n algemeenheid kun je stellen dat er in ieder geval aan twee punten moet zijn voldaan, namelijk:

* Het verhoor moet op een verantwoorde wijze zijn afgenomen.

* De uitkomst van het verhoor dient een weergave te zijn van de waarheid, of in ieder geval de waarheid zoveel mogelijk te benaderen.

Wanneer de uitkomst van een verhoor aan de verwachtingen van de politie voldoet of past bij reeds bekende onderzoeksresultaten, betekent dat niet per definitie dat het verhoor een goed verhoor is geweest. Ik denk dat de politie op dit punt nogal eens de mist in gaat. Het komt mijns inziens geregeld voor dat de politie op voorhand al min of meer vaststelt hoe de verklaring zou moeten luiden. Die vaststelling wordt gebaseerd op reeds bekende feiten. De objectiviteit kan hierbij gemakkelijk in het gedrang komen. Men hoort wat men wil horen en men negeert wat niet of niet helemaal past. Soms bestaat de neiging om de verklaringen 'kloppend' te maken. Dit gevaar is vooral aanwezig wanneer dezelfde persoon voor een tweede of derde keer gehoord wordt, terwijl hij daarbij terugkomt van een eerder afgelegde verklaring.

Ik wil proberen het bovenstaande met een (gechargeerd) voorbeeld te verduidelijken. Stel dat de politie een melding krijgt dat er een kind misbruikt is

* Coördinerend rechercheur zeden- en jeugdzaken bij de regiopolitie Groningen. 
door een man in een park. De melding bestaat onder andere ook uit een signalement van de dader. Dit signalement luidt als volgt:

Een man van ongeveer 50 jaar oud met een dikke buik en een grote snor.

Twee weken later dient zich een nieuwe zaak aan. In een woning, gelegen nabij eerdergenoemd park worden twee kinderen door een man misbruikt. Beide kinderen worden gehoord. Zij kunnen de woning waarin het gebeuren heeft plaatsgevonden niet aanwijzen maar ze kunnen wel een signalement van de betreffende man geven. Kind 1 zegt daarover:

Een oudere man met een dikke buik en een grote snor.

Kind 2 geeft een ander signalement op, namelijk:

Een oudere man van ongeveer 50 jaar oud met een baard en hetzelfde postuur als mijn vader. (De vader van het kind heeft geen dikke buik.)

Het signalement van kind 1 past dus zeer goed bij het signalement uit de eerdere zaak. De politie wil beide zaken uiteraard graag oplossen. Dit soort feiten geeft immers veelonrust in de betreffende buurt. De politie kent een eigenaardige man die in de buurt van het park woont. Deze man heeft een dikke buik, een grote snor en is exact vijftig jaar oud. Hij is al eens eerder in verband gebracht met ontucht met kinderen. Heeft de politie hiermee een verdachte?

In ons strafrechtstelsel is er sprake van een verdachte als er een redelijk vermoeden van schuld aan enig strafbaar feit bestaat. Uiteraard is het de politie opgevallen dat de twee kinderen uit de tweede zaak verschillende signalementen geven. De politie besluit daarom nog maar eens met kind 2 te gaan praten. Het kind wordt gevraagd of de baard geen snor moet zijn. Ook wordt gevraagd of de buik van de man toch niet wat dikker was dan de buik van zijn of haar vader. Het kind lost de verwachtingen in. De drie verklaringen komen nu aardig overeen en het signalement wordt derhalve bijgesteld. Beide zaken worden aanelkaar gekoppeld.

De vraag waarom er niet nogmaals met kind 1 wordt gepraat dringt zich op. Moet de snor soms geen baard zijn en had die man wel zo'n dikke buik? In de drang om de zaak op te lossen wordt hier een kardinale fout gemaakt met mogelijke kwalijke gevolgen, bijvoorbeeld aanhouding van 'de verdachte'. 


\section{Goed verhoor}

Hoe moet het dan wel of, beter gezegd, hoe zou het kunnen? Eerst dienen zo objectief mogelijk de exacte feiten en omstandigheden van beide voorvallen vastgesteld te worden; vervolgens kan er gekeken worden naar een mogelijk verband tussen beide zaken. Misschien is het eerste voorval wel verzonnen. Misschien fantaseren de kinderen uit het tweede voorval wel naar aanleiding van het eerste.

Het is dus van groot belang dat er goede verhoren plaatsvinden. En dat brengt mij terug bij de vraag wat een goed verhoor is. Ik ben er van overtuigd dat de politie er naar streeft om verhoren zo goed mogelijk af te nemen en op schrift te stellen, maar kan er niet om heen dat er fouten gemaakt worden.

\section{Problemen}

Ik wil hier nader ingaan op de wijze waarop de politie thans verhoren van jonge kinderen afneemt. Ik hoef daarbij niet meer duidelijk te maken dat er in onze maatschappij veel kinderen zijn die het slachtoffer worden van een ernstig misdrijf (zoals seksueel misbruik). Dit is geen nieuw probleem; het probleem is echter pas de laatste vijftien tot twintig jaar in alle hevigheid naar buiten gekomen. Er is eindelijk enig inzicht onstaan in de aard en omvang van deze problematiek. De politie heeft dan ook te maken gehad met een enorme toename in het aantal meldingen en aangiften op het terrein van seksueel misbruik, waaronder dus seksueel misbruik van jonge kinderen. Het besef dat deze problematiek een specifieke benadering vraagt is overduidelijk aanwezig.

Het horen van jonge kinderen is een taak die voornamelijk is toebedeeld aan rechercheurs van de afdelingen Zeden en Jeugd. Voorheen geschiedde dit niet volgens een vaste, beproefde methode. Politiemensen die dit soort verhoren afnamen deden het ieder op hun eigen manier, waarbij overigens niet meteen gezegd is dat dit niet de goede manier was. De rechercheur ging met het kind praten en legde dit vaak achteraf schriftelijk vast. Opname-apparatuur werd slechts in uitzonderingsgevallen gebruikt. Het gevolg was vaak dat het niet altijd een verklaring 'des kinds' werd. De rechercheur legde het gesprek geheel of gedeeltelijk in eigen bewoordingen vast. Zo kon je bijvoorbeeld in een verklaring van een 4-jarig meisje lezen: 'Die meneer liet zijn geslachtsdelen zien en heeft ook aan mijn geslachtsdeel gevoeld'.

Dit staat misschien wel keurig in een proces-verbaal, maar is natuurlijk niet op die manier door een 4-jarig meisje gezegd. Ook werd de vraagstelling door de rechercheur niet vastgelegd. Controle op deze verhoren was dan ook niet of 
nauwelijks mogelijk. Deze manier van werken bood advocaten van verdachten in een later stadium de mogelijkheid om de verklaringen van de kinderen in twijfel te trekken. Daarnaast werd vaak geopperd dat het kind suggestief bevraagd zou zijn. Wanneer de rechter vervolgens die twijfel overnam, kon er uiteraard niet tot een veroordeling worden overgegaan.

Er was echter meer aan de hand. Er ontstond een brede discussie over het horen van kinderen. Velen vonden dat het geen taak van de politie behoorde te zijn om jonge kinderen te ondervragen over zoiets traumatiserends als seksueel misbruik. Politiemensen waren er immers niet voor opgeleid en de verhoren zouden bovendien schadelijk zijn voor het kind. Zelf deel ik deze opvatting niet. Ik ben echter wel van mening dat het verhoor - zoals eerder gezegd - op een juiste en verantwoorde manier moet worden afgenomen. Zo'n verhoor levert geen trauma's op. Ik denk zelfs dat een verhoor een goede uitwerking op een kind kan hebben. Kinderen wordt immers van jongs af aan geleerd dat de politie er onder andere voor is om mensen die iets verkeerds hebben gedaan op te pakken c.q. op hun gedrag aan te spreken. Een kind vindt het vaak zelfs prettig om zijn nare ervaringen aan de politie te vertellen. Trauma's kunnen ontstaan als de verhoren op een verkeerde manier worden afgenomen. En aan de manier waarop dat gebeurde viel inderdaad het nodige af te dingen.

\section{Verbeteringen}

Een heel belangrijk aspect in de verbetering van die verhoren is geweest: het omgaan met de gevoelens van disloyaliteit die kinderen kunnen hebben. Bij seksueel misbruik van kinderen is immers maar al te vaak iemand uit de directe leef of woonomgeving verantwoordelijk voor het misbruik. Voor alle duidelijkheid wil ik stellen dat het geen aanbeveling verdient, om alle kinderen die seksueel misbruikt zijn of waarvan dat wordt vermoed door de politie in een interviewstudio te horen. Deze methode moet en mag alleen gebruikt worden als dat noodzakelijk is en er aan bepaalde criteria is voldaan. Hier kom ik nog op terug.

Voorafgaande aan de methode van verhoren zoals die thans bij de politie gehanteerd kan worden hebben we een periode gehad waarin deskundigen, of zogenaamde deskundigen, de politie bijstonden in het verhoren van kinderen. De taak van de politie werd dus eigenlijk door externe deskundigen overgenomen. Met wisselend succes. De deskundigen bleken lang niet altijd op één lijn te zitten en bekritiseerden elkaar vaak hevig. Na verloop van tijd bleek dan ook dat het inschakelen van deskundigen geen uitkomst bood. Het deed bovendien afbreuk aan het uitgangspunt dat verhoren binnen een strafprocesrechtelijk kader 
door politie-ambtenaren afgenomen behoren te worden. Zij zijn immers degenen die weten welke informatie in het kader van het onderzoek relevant is en op welke wijze de verkregen informatie moet worden weergegeven.

Op zich is de constatering dat de politie de nodige kennis en vaardigheden miste overigens een juiste geweest. Men heeft zich daarom op het standpunt gesteld dat de politie zelf de nodige kennis en vaardigheden maar moest zien te verwerven. Het voortouw werd hier genomen door de politie te Amsterdam, alwaar in 1989 een experiment werd opgestart. Er werd een nieuwe verhoormethode ontwikkeld. De experimentele fase ligt reeds ver achter ons en de methode is daar waar nodig bijgesteld en aangepast. Deze ontwikkeling is nog steeds gaande.

De 'Amsterdamse' ervaringen waren dermate goed dat het project landelijk navolging heeft gekregen. In den lande zijn inmiddels meerdere interviewstudio's geopend, waaronder één in Groningen.

\section{De interviewstudio}

Wat houdt zo'n interviewstudio nou precies in? Van de inrichting valt vrij gemakkelijk een voorstelling te maken. De studio bestaat uit twee ruimten. Een kindvriendelijke kamer en een regiekamer, van waaruit de opnamen worden verzorgd. Tussen beide ruimten is een zogenaamd one-way-screen aangebracht. De kindvriendelijkheid komt tot uitdrukking in de gehele inrichting van de kamer. Er zijn vrolijke, aansprekende kleuren gebruikt. Het meubilair is aangepast en er zijn diverse hulpmiddelen, zoals spel- en tekenmateriaal. Met nadruk wil ik opmerken dat er geen 'anatomisch correcte poppen' worden gebruikt. Deze poppen zijn in navolging van de Amerikanen in Nederland gebruikt om diagnoses te stellen. De methode is echter ondeugdelijk gebleken en het gebruik van de poppen is in ieder geval voor justitiële doeleinden afgezworen. Wel gebruiken wij tekeningen waarop een kind bepaalde handelingen kan aanwijzen of aankruisen. Bovendien zijn de tekeningen geschikt om het kind bepaalde lichaamsdelen te laten benoemen.

Horen in een interviewstudio is geen tovermiddel. Het is niet zo dat een verhoor in de studio altijd een juist verhaal oplevert. Ook wordt niet ieder te horen kind naar de studio gebracht om daar gehoord te worden. Dit moet iedere keer eerst zorgvuldig worden afgewogen. Wanneer een kind bijvoorbeeld geconfronteerd werd met een 'schennispleger' en het kind heeft de ouders reeds verteld wat er is gebeurd en hoe de man er uitzag, dan kan veelal worden volstaan met een gesprek met de ouders. Het kind hoeft dan niet meer door de politie, laat staan in een studio, verhoord te worden. 
De verhoren in de studio worden uitsluitend afgenomen door rechercheurs die een bepaald trainingsschema hebben doorlopen en na gebleken geschiktheid een certificaat hebben gekregen. Het doel van de training is onder meer Jeugd- en zedenrechercheurs te leren de belevingswereld van jonge kinderen op dusdanige wijze te vertalen dat voor justitieel gebruik geschikte verklaringen worden verkregen, terwijl het kind er geen nare of traumatische ervaringen aan overhoudt.

Voor het verhoor van een kind in de studio gelden een aantal criteria. De belangrijkste daarvan zijn:

* Er dient sprake te zijn van een ernstig misdrijf of een vermoeden daarvan;

* er dient sprake te zijn van een ingrijpende gebeurtenis met een persoonlijke betrokkenheid van en mogelijk ernstige gevolgen voor het kind. Het gaat hierbij om kinderen in de leeftijd van ongeveer 4 tot ongeveer 12 jaar oud.

Aan de beslissing om een kind in de studio te horen gaan twee overwegingen vooraf.

* Welk belang wordt gediend met het verhoor van het kind?

Leidt deze overweging tot het voornemen het kind te horen, dan wordt de volgende overweging relevant:

* Welk doel wordt nagestreefd met het vastleggen van dit verhoor door een daarvoor getrainde rechercheur?

Bij de eerste overweging wordt zowel naar het belang van het kind als het belang van het onderzoek gekeken. Hierbij weegt het belang van het kind het zwaarst. De uiteindelijke beslissing ligt bij de officier van justitie. Daarnaast is schriftelijke toestemming vereist van:

* De gezagsdragers van de te horen minderjarige of

* de directeur van de Raad voor de Kinderbescherming of de kinderrechter, indien er een kinderbeschermingsmaatregel op de betrokken minderjarige van kracht is.

Uiteraard kunnen ook de gezagsdragers, of één van hen verdachte zijn. Wanneer één van hen verdachte is, is toestemming van de niet-verdachte gezagsdrager voldoende. Zijn beiden verdachte dan moet er vervangende toestemming gegeven worden. De behandelende officier van justitie kan daartoe de betrokken 
minderjarige in dat geval voorlopig toevertrouwen aan de Raad voor de Kinderbescherming.

\section{Tijdig doorspelen}

Er zijn overigens ook zaken die zonder bemoeienis of inmenging van de politie behandeld kunnen worden. Dit heeft in veel gevallen zelfs de voorkeur. Wanneer er in de hulpverlenende sfeer oplossingen gevonden kunnen worden dan juich ik dat van harte toe. Helaas lukt dat niet altijd en dan kan een politieonderzoek uitkomst bieden. In die gevallen wordt nog te vaak ten onrechte de zaak niet of te laat doorgespeeld. Ik denk dat juist dit traumatiserend kan werken. Ik vind dat er een bepaalde bereidheid, mogelijk zelfs een plicht, moet zijn om een zaak door te spelen wanneer men zelf geen duidelijkheid kan krijgen of geen oplossing kan bewerkstelligen. Politie en justitie beschikken immers over machtsmiddelen om dwingend in gesloten gezinssituaties of andersoortige relatievormen in te grijpen. Juist die dwang wordt in bepaalde gevallen als noodzakelijk gezien om een doorbraak te forceren. Het inschakelen van politie en justitie door andere instellingen of instanties stuit echter nog steeds op weerstand. Deels begrijpelijk, maar deels ook niet. Wij zien regelmatig in onderzoeken dat er al een tijdlang door anderen geprobeerd is om een oplossing te vinden en dat wij vervolgens moeten constateren dat we eerder een einde aan de situatie hadden kunnen maken, als we in een eerder stadium ingeschakeld waren. Ik heb inmiddels ervaren dat mede door de verhoormethode dit beeld positiever is geworden. Als er andere oplossingen gecreëerd worden dan het inschakelen van politie of justitie is dat natuurlijk ook prima. Zo is er bijvoorbeeld al gepleit voor ruimere bevoegdheden voor de Bureaus Vertrouwensartsen.

\section{Meer voordelen verhoorstudio}

Ik heb reeds een aantal voordelen van de verhoormethode geschetst. Er zijn nog een aantal voordelen die ik nog niet heb genoemd. Naast de verbale worden nu namelijk ook de non-verbale uitingen van het kind zichtbaar. Soms vindt een kind het moeilijk om bepaalde details te vertellen en wil het liever iets voordoen. Dit is in een verklaring op papier moeilijk vast te leggen. Een videocamera legt het exact vast. Verder kan een gedragswetenschappelijk deskundige desgewenst een interpretatie van het gedrag van het kind geven aan de hand van het videomateriaal. Uiteraard blijft het ook mogelijk om in speciale gevallen een extern deskundige het verhoor te laten afnemen. 
Vanzelfsprekend is het gebruik van de vervaardigde videobanden goed afgeschermd. De banden worden gewaarmerkt en bewaard in een kluis op het politiebureau. Er mogen geen kopieën van de band gemaakt worden. De band kan alleen gebruikt worden in het kader van een strafrechterlijk onderzoek, het gerechtelijk vooronderzoek en het onderzoek ter terechtzitting. Ook de verdachte of diens advocaat kunnen vragen de band te mogen bekijken. Hierover beslist de officier van justitie en/of de rechter-commissaris. Wanneer derden, waaronder ook hulpverleners worden gerekend, de band willen zien, moet er ook toestemming zijn van de gezagsdragers over het kind. Bij een eventuele vertoning is altijd een rechercheur aanwezig.

\section{Ervaringen}

Ik heb zelf de training om de verhoren te mogen afnemen gevolgd. Naast het theoretische gedeelte bestond de training uit een groot praktijkgedeelte. In dit praktijkgedeelte werden eerst gesprekken geoefend met kinderen die zelf geen slachtoffer waren.

Als cursist kreeg je de opdracht om met het kind te praten over een leuke en een niet leuke ervaring. De keuze van de onderwerpen was daarbij aan het kind. De cursist moest vervolgens proberen zoveel mogelijk details over de door de kinderen aangegeven onderwerpen te weten te komen. Deze verhoren werden daarna zeer kritisch nabesproken. Op het moment dat ik de cursus volgde werkte ik reeds ruim elf jaar bij de Zeden- en jeugdpolitie. In die elf jaar had ik al heel wat gesprekken met kinderen gevoerd. Dit nam niet weg dat er voor mij nog erg veel te leren en te verbeteren viel. Door de cursus ben ik me er meer bewust van geworden wat de betekenis van een verhoor voor het kind is en van de effecten die mijn gedrag op het kind kunnen hebben. Het regelmatig terugzien en nabespreken van de verhoren heeft mij bovendien veel kritischer gemaakt ten aanzien van mijn eigen gedrag.

Dat ik de nieuwe verhoormethode als een enorme verbetering zie, moge duidelijk zijn. Dit is echter niet het belangrijkste. Veel belangrijker is wat de kinderen er zelf van vinden. Er zijn inmiddels al vele honderden kinderen in de diverse studio's gehoord. De ervaringen zijn zeer positief, vanuit justitie, vanuit de hulpverlening en vanuit de kinderen zelf. Er wordt tegenover de kinderen niet geheimzinnig over gedaan. Voorafgaand aan het verhoor mogen ze de studio en de regiekamer bekijken. Het gebruik van de apparatuur wordt - voor zover ze dat kunnen begrijpen - uitgelegd. In de praktijk is gebleken dat kinderen zich in de studio over het algemeen razendsnel op hun gemak voelen en dat de omstandigheden binnen de studio bevorderen dat het kind zijn verhaal doet. Het 
komt zelfs voor dat kinderen in de studio willen blijven om verder te spelen en te praten of vragen wanneer ze nog eens terug mogen komen. 


\section{Voorbereiding}

Zoals bij zoveel andere zaken is bij een studioverhoor een goede voorbereiding van enorm belang. Is een kind slecht voorbereid, dan levert dit vrijwel altijd een moeizaam verhoor op. Zowel de ouders als de verbalisant kunnen het kind voorbereiden op het verhoor. Voorbereiding door een verbalisant kent voordelen: een neutralere introductie van het verhoor; het kind ziet tijdens de voorbereiding al een politiefunctionaris (zonder uniform!) en kan eventueel vragen over het verhoor stellen. Het kind moet weten dat het gaat praten met iemand van de politie op een politiebureau. Het moet dus de positie van de interviewer kennen, zodat het niet denkt dat het met een hulpverlener of een dokter te maken heeft. Het kind moet verder weten dat het naar een 'praatkamer' gaat waar ook spelmateriaal is. Door de nadruk te leggen op praten wordt voorkomen dat het kind denkt dat het alleen maar komt om te spelen. Het kind moet ook weten waarover het komt praten. Wanneer het kind dit weet, vindt het verhoor voor het kind plaats binnen een duidelijk kader. Ontbreekt dit kader en is het gespreksonderwerp voor het kind onduidelijk, dan wordt het verhoor hierdoor zeer bemoeilijkt: het kind vertelt moeizamer of helemaal niet; het weet immers niet waar het om gaat. Wanneer het kind niet weet dat bijvoorbeeld verwacht wordt dat het vertelt over een seksueel-misbruiksituatie, ligt het niet voor de hand dat het dit uit zichzelf gaat vertellen.

Degene die het kind voorbereidt moet het kind vertellen dat het alles mag zeggen, maar dat het niet om een test gaat. Het is van belang dat de ouders het kind niet onder druk zetten om te presteren. Een enkele keer gebeurt dit wel eens. Zo heb ik eens een meisje gehoord die kwam opdraven in haar zondagse jurk. Haar ouders hadden haar beloofd dat ze, indien ze alles zou vertellen, nadien de stad in zouden gaan om een nieuwe pop te kopen.

\section{Verloop verhoor}

Het verhoor vangt in principe aan met een introductiegesprek. Doelstellingen hierbij zijn: kennismaken, vertrouwen winnen, niveau inschatten, duidelijkheid geven over de rol van de interviewer en de bedoeling van het contact. Door met het kind te praten en te spelen toont de interviewer belangstelling en probeert hij een indruk te krijgen van het kind. Het te spelen spel mag niet te lang duren en te vermoeiend zijn. Het is van belang om ook in de introductie open vragen te stellen. Hiermee zet de interviewer een trend. Het kind wordt vanaf het begin aangezet tot vertellen en went eraan dat de interviewer uitgebreide antwoorden van hem of haar verwacht. 
$\mathrm{Na}$ de introductie volgt het zaakgerichte gedeelte. Het uitgangspunt hierbij is dat het kind de gelegenheid krijgt een betrouwbare verklaring af te leggen in eigen woorden en met zoveel mogelijk details. De opening van het zaakgericht gedeelte moet in ieder geval objectief zijn, zonder informatie over de verdachte of het verdachte feit in te brengen.

Vervolgens zijn er 3 scenario's te onderscheiden:

a. Het kind gaat praten over 'de zaak'.

b. Het kind slaat niet aan, maar het lukt later alsnog.

c. Het kind praat niet en er moet voorinformatie worden ingebracht.

\section{Scenario A: Het kind begint te praten over de zaak}

Om zo betrouwbaar mogelijke informatie te verkrijgen wordt het kind gevraagd zoveel mogelijk uit zichzelf te vertellen. De informatie uit deze 'free recall' is het meest betrouwbare onderdeel van de verklaring. De verklaring dient verder voorzien te worden van zoveel mogelijk feiten en details. Hiernaar wordt gevraagd door middel van open vragen. Om zo betrouwbaar mogelijke informatie te verkrijgen geeft de interviewer het kind drie instructies. Deze instructies zijn:

1. Het kind toestemming geven om door de interviewer gemaakte fouten te corrigeren.

2. Het kind vertellen dat het de interviewer mag vragen om uitleg, als het een vraag niet begrijpt.

3. Het kind toestemming geven om te zeggen dat het een antwoord op een vraag niet weet.

\section{Scenario B: Het kind reageert niet op 'waarover het komt praten' (de indirecte manier)}

Slaan de genoemde openingsmogelijkheden niet aan, dan kan scenariob. worden ingezet. Uitgangspunt van dit scenario is, om op een meer indirecte wijze met het kind in gesprek te komen over zaken uit de aangifte: de verdachte, de verdachte gebeurtenis, de betreffende locatie etc., zonder dat de interviewer voorinformatie inbrengt omtrent de verdachte of de verdachte handelingen.

\section{Scenario $C$ : Het inbrengen van voorinformatie}

Als het kind niets verteld heeft na scenario b. doorlopen te hebben, kan eventueel worden gekozen voor scenario c. Als wordt besloten om het kind met voorinformatie te confronteren, dan moet dit op zorgvuldige en zo objectief mogelijke wijze gebeuren. Het is van belang niet de naam van de verdachte en ook niet de betreffende handelingen te noemen. De interviewer kan wel vragen 
of er iets op een bepaalde locatie, bijvoorbeeld in de speeltuin, is gebeurd. Bij deze, naar verhouding suggestieve aanpak, wordt de objectiviteit toch nog zoveel mogelijk gewaarborgd.

\section{Weerstand}

De boven omschreven scenario's gaan er van uit dat er een gesprek over het misbruik volgt. Toch kan het uiteraard voorkomen dat het niet lukt om daarover met het kind aan de praat te komen. Er kunnen bepaalde weerstanden bij het kind bestaan die het onmogelijk maken om tot een gesprek over het misbruik te komen. Dit betekent niet dat de interviewer op dat moment zijn werk niet goed doet. Het kind bepaalt hoe dan ook zelf of het wil vertellen. In het algemeen geldt met betrekking tot weerstand dat je er in het interview niet omheen moet gaan maar het aan moet pakken. Niet-bewerkte weerstanden en emoties zullen immers een blijvend obstakel vormen voor de rest van het verhoor. Tijdens het verhoor kan de weerstand besproken worden in de hoop dat het opgeruimd kan worden. Is de weerstand echter te groot, dan kan het zijn dat je er niet doorheen komt. De interviewer dient dit te respecteren en te accepteren. In geen geval mag de weerstand doorbroken worden om koste wat het kost het verhaal te willen horen. Je kunt een heel goed verhoor afnemen waar niets uitkomt. Dit is wellicht beter dan een zeer slecht verhoor waar wel wat uitkomt. Een perfect verhoor bestaat naar mijn mening niet, maar we moeten er wel alles aan (blijven) doen om het zo dicht mogelijk te benaderen.

\section{Slot}

Tot slot wil ik nog het volgende opmerken. Doordat er zoveel kinderen slachtoffer zijn of zijn geweest van seksueel geweld lijkt het wel alsof kinderen in een 'verziekte' maatschappij opgroeien. Zeker als je zelf in je werk met deze materie vaak geconfronteerd wordt. Ik hecht er daarom aan om te benadrukken dat de meerderheid van de kinderen in een liefdevolle, vertrouwde en beschermde omgeving opgroeit. Het merendeel van de kinderen ziet dus gelukkig de interviewstudio niet van de binnenkant. Schattingen spreken van 1 op de 6 kinderen die met seksueel misbruik te maken krijgen. Of dat getal klopt is maar de vraag. Het klinkt ernstig, maar je kunt ook zeggen dat van iedere 600 kinderen er 500 geen slachtoffer zijn ofzijn geweest. Wat blijft, is dat ieder geval van (seksueel) misbruik er één teveel is. 